\title{
A AMÉRICA LATINA NO SÉCULO XIX. UMA MONARQUIA EM FACE DE VÁRIAS REPUBLICAS.
}

\author{
JOSE RIBEIRO JÚNIOR \\ da Faculdade de Filosofia, Ciências e Letras de Assis.
}

$O$ assunto a ser tratado nesta oportunidade oferece-nos o ensêjo de enfocar o mundo latino-americano em conjunto, possibilitando uma compreensão global da sua História no século passado.

A América Latina do século XIX passou por transformações substanciais em sua estrutura econômica, social e principalmente política.

Não podemos, nem temos a pretensão de esgotar o assunto, pois, muitas pesquisas originais precisam ainda ser feitas. São poucos e insuficientes os trabalhos histórico-científicos existentes, estudando a América Latina do século XIX como um todo (1). Assim, a ausência de bibliografia satisfatória dificulta-nos um trabalho completo sôbre o assunto. A nossa abordagem do tema circunscreve-se ao esfôrço de reflexão de um brasileiro do século XX que busca na História o esclarecimento do estado presente.

A América Latina vive, atualmente, momentos decisivos da sua evolução histórica e necessita de uma conscientização dos países que a compõe e uma conseqüente tomada de posição coletiva. A retrospectiva histórica é necessária na medida em que traz à tona problemas de profundas raízes, incompreensíveis sem a busca de suas origens.

$\mathrm{Na}$ problemática do século XIX procuraremos levantar e resolver, na medida do possível, algumas questões em tôrno de três aspectos:

1. - Verificar como e por quê a América portuguêsa estabeleceu e conservou a Monarquia e sua unidade territorial após 1822, enquanto que a América espanhola após 1810 transformou-se num conjunto de repúblicas fragmentadas.

(1). - A malor parte dos historiadores e soclólogos de língua espanhola raramente colocam o Brasil no complexo dos países da América Latina. 
2. - Mostrar quais as influências externas comuns atuantes no século XIX latino-americano.

3. - Observar as relações diplomáticas entre a Monarquia brasileira e as várias repúblicas, tentando estabelecer influências recíprocas.

Daremos, portanto, ao assunto, um enfoque quase que exclusivamente político-ideológico num estudo paralelo entre os países latino-americanos.

\section{1. - A Independência na América Latina.}

Entre os fins do século XV e início do XVI deu-se a ocupação da América pelas monarquias ibéricas. O Nôvo Mundo foi descoberto numa época de expansão econômica da Europa ocidental. A colonização se fêz sob o signo do capitalismo comercial. Este é o primeiro ponto comum a tôda a América Latina. A América ibérica tinha que servir à mesma finalidade: devia fornecer ao mercado europeu produtos tropicais de alto valor comercial, metais nobres e pedras preciosas. Não entraremos nos matizes de forma colonizadora que diferem, é verdade, mas tanto Espanha como Portugal constituíram suas colônias com aquêles objetivos. Assim, as futuras nações tiveram semelhante formação colonial enquanto instrumentos dos dois países colonizadores.

Na segunda metade do século XVIII, quando a América começava a adquirir condições para sua autonomia, a Europa também assistia a transformações importantes em sua estrutura. A partir de 1750 houve a primeira fase da Revolução Industrial e em 1789 eclodiu a Revolução francesa marcando a ascensão da burguesia.

Latino-americanos que participaram do processo de Independência como Miranda, O'Higgins, Bolivar, José Bonifácio e outros, estudando ou viajando pela Europa, tomaram contacto com essas transformações e empolgaram-se com as novas idéias liberais.

Na América, as colônias inglêsas lançaram a sua declaração de Independência em 1776.

O exemplo da Independência dos Estados Unidos da América e a ideologia da Revolução francesa, agitaram os espíritos americanos mais esclarecidos, despertando o mundo colonial. O manifesto de Miranda, o precursor, entusiasmado com a Independência dos Estados Unidos da América e a revolta contra a opressiva taxação nas Minas Gerais foram os primeiros sintomas sérios de uma tomada de 
consciência na América Latina. Não se pode dizer, porém, que tivesse havido uma tomada de consciência coletiva; nem mesmo da elite mazomba ou crioula. Por outro lado, não havia, como nas colônias anglo-americanas uma estrutura econômica e social propícia à independência. Ao contrário, a economia latino-americana era baseada nos metais preciosos, na grande lavoura, e seu comércio era fator de dependência dos mercados externos ligados às metrópoles. Muitos nacionais estavam ligados ao sistema comercial da metrópole. Por isso os projetos de Miranda, por exemplo, expressão de um pensamento político hispano-americano original, não encontravam ressonância considerável na América. As condições internas para uma autonomia não se cristalizaram antes do início do século XIX. Ressalta um historiador contemporârieo que no século XVIII as novas idéias liberais no mundo hispano-americano eram propostas pela própria metrópole e fruto da filosofia das luzes (2). Em 1783 Aranda, ministro de Carlos III propôs a formação na América de monarquias com infantes espanhóis sob a égide do rei da Espanha. Em 1794 Godói teria proposto a mesma idéia mas também não foi aceita pela Corôa espanhola.

Em Portugal vários políticos, entre êles D. Rodrigo de Souza Coutinho, aventaram a possibilidade de transferir a sede da monarquia portuguêsa para a parte mais rica do seu império, o Brasil (3). O plano foi abandonado e o Brasil era ainda no início do século XIX, um vice-reino.

Na América espanhola, no último quartel do século XVIII foram criadas por Carlos III as Intendências que absorveram em parte as atribuições político-administrativas dos vice-reinados (4).

Retomemos o mundo europeu dos fins do século XVIII. Destacam-se duas grandes potências: a Inglaterra industrializando-se e expandindo seus mercados e círculos de influêńcia política; a França impregnada dos ideais liberais, tendo uma burguesia que queria aumentar o seu raio de ação. No início do século XIX Napoleâo tem o propósito de conseguir para a França a hegemonia do mundo. Tentando ser a primeira potência européia esbarra no leão britânico. Uma luta titânica de imperialismos tem lugar na Europa. O que a diplomacia não resolveu foi resolvido pelas armas. Em 1806 Napoleão decretou o Bloqueio Continental. As conseqüências advindas dessa decisão são de transcedental importância para o estudo da Independência da América Latina.

(2). - Chaunu (Pierre), L'Amerique et les Ameriques. Paris, Armand Collin, 1964. Passim.

(3). - Cf. Lima (Oliveira) $D$. João VI no Brasil. Rio de Janeiro, José Olímplo, 1945,3 volumes, 19 vol.

(4). - Interessante é notar a fragmentação da América espanhola obedecendo no geral à divisão feita por Intendências. 
Embora a Inglaterra conseguisse furar o Bloqueio na Europa, fato demonstrado pelos trabalhos de Jorge de Macedo (5) e Pinto de Aguiar (6), a indústria inglêsa necessitava de maiores mercados. Desde meados do século XVIII dirigira suas atenções para o Nôvo Mundo Ibérico, desfrutando das vantagens da vassalagem econômica portuguêsa. Contrabandeava impunemente no Brasil e procurava dominar o comércio hispano-americano principalmente no Prata (7).

Portugal era ponto estratégico na consolidação da manobra napoleônica. D. João depois de muitas vacilações optou pelo apôio à Inglaterra e por sugestão desta retirou-se para o Brasil em fins de 1807, tendo Junot quase obstado a sua retirada. Transferia-se para o Brasil tôda a família real para uma estada mais duradoura do que poderia supor. A dinastia bragantina fincaria fundos alicerces no Brasil.

$\mathrm{Na}$ Espanha, depois do apôio do ministro Godói ao plano de Napoleão, Carlos IV abdicou em favor de seu filho Fernando VII. Porém, na degradante entrevista de Bayonne entre Carlos IV, Fernando VII e Napoleão concluiu-se pela permanência do primeiro no trono e logo depois Carlos IV novamente abdicou, desta feita em nome de José Bonaparte, irmão do Imperador francês.

Em Portugal os exércitos dos comandantes inglêses e soldados portuguêses repeliram a invasão de Junot e depois as de Soult e Massena. Mesmo dépois da expulsão dos franceses do território português as fôrças militares ficaram sob o comando de Beresford cujo procedimento foi uma das fortes motivações da Revolução do Pôrto de 1820.

Na Espanha os espanhóis não aceitaram o govêrno de José I. Manifestaram solidariedade a Fernando VII e instalaram uma junta governativa central de caráter revolucionário. A restauração do monarca deu-se em 1814. Houve depois uma revolução liberal em 1820 anterior à de Portugal. Veio posteriormente a reação absolutista em 1823. Com a morte de Fernando VII em 1833, cessou a ameaça de reconquista das antigas colônias.

No mesmo momento em que as metrópoles estavam sob o domínio napoleônico iniciou-se, efetivamente, nas colônias ibéricas, o processo da sua emancipação.

Cada província hispano-americana devia escolher entre José I ou sublevar-se em nome de Fernando VII, legítimo ocupante do trono espanhol.

(5). - Macedo (Jorge Borges de), O Bloquèio Continental. Economia e guerra peninsular. Lisboa, Delfos, 1962.

(6). - Pinto de Aguiar, Abertura dos portos do Brasil (Cairú $e$ os ingléses). Salvador, Progresso, 1960.

(7). - Cf. Sodré (Nelson Werneck), As Razôes da Independência. Rio de Janeiro, Civilizaçāo Braslleira, 1965. 
Instalaram-se na América espanhola, a exemplo da Espanha, juntas governativas. Estas repeliram emissários do rei usurpador e manifestaram seu apôio a Fernando VII. Os secessionisias, maçons das grandes cidades da América espanhola, advogados, padres, etc., começam a se manifestar. O movimento de separação adquire expressão e alastra-se. Em Buenos Aires em 25 de maio de 1810, uma junta insurrecional depôs o vice-rei Cisneros. O Chile seguiu, logo após, êsse exemplo. No México Iturrigaray presidia uma junta central eleita pelos cabildos. Hidalgo e Morelos iniciaram movimentos anti-conservadores. Mais tarde, Itúrbide proclamou-se rei de una monarquia efêmera. Caracas proclamou sua independência em 5 de julho de 1811. A América espanhola, enfim, ficou tôda envolvida na luta pela emancipação, fruto do isolamento causado pela situação na Metrópole. A Independência da América hispânica só veio, porém, depois de muita luta e muito sangue derramado. O Peru, última província a proclamar sua independência, o fêz em 1824 depois da batalha de Ayacucho.

\section{2. - A independência do Brasil: conservação da monarquia $e$ da unidade territorial.}

No Brasil, a transmigração da Família Real diferenciou completamente o processo da Independência do resto da América. Com a vinda da Côrte, pode-se afirmar, terminou o período colonial brasileiro e inaugurou-se a fase independente. De fato, o Brasil transformou-se em centro do Império português. A consciência separatista foi sufocada pela presença do monarca e confiança em dias melhores. A abertura dos portos brasileiros ao comércio livre, o transplante do organismo administrativo para a colônia, a elevação do Brasil a Reino Unido em 1815 transformavam o status político e econômico do Brasil.

Depois da Revolução liberal do Pôrto em 1820 as Côrtes Gerais exigiam a volta de D. João VI. A posterior ação das Côrtes, assumindo o poder de fato, foi orientada no sentido de anular as concessões feitas ao Brasil no período Joanino. Essas intenções explicam-se pelo exame dos elementos que fizeram a revolução. A maior parte era da burguesia que vivia em função do monopólio comercial e que tinha no Brasil a sua maior fonte de renda. Mas, já era tarde, o processo era irreversível. A burguesia chamada liberal portuguésa, paradoxalmente reacionária, encontrava um Brasil consciente dos seus direitos e nesse momento tôdas as classes sociais coesas em tôrno de D. Pedro. 
Proclamada a Independência em 1822 , de forma pacífica em relação à América Latina, D. Pedro foi proclamado Imperador do Brasil. Proclamou-se a Independência mas o regime monárquico transplantado da Europa continuou no Brasil. No momento da Independência não se pôs o problema da forma política. Com a ideologia monárquica enraizada a maioria do povo brasileiro e os políticos apoiaram o líder da emancipação política do Brasil que era um príncipe. Mesmo os elementos mais radicais concentravam-se mais na idéia de federalismo do que pròpriamente na República com tôdas as suas implicações democráticas. Foi dado um crédito ao liberalismo de D. Pedro I e esperava-se muito da prometida Constituição. Por outro lado, a estrutura latifundiária e escravista apoiava a forma monárquica pelo sentido conservador e pela aparência legal de que era revestida a pessoa do príncipe. Ademais o Brasil recém-independente tinha duas tarefas a cumprir. Consolidar a independência internamente e através do reconhecimento do poder central, pelas províncias recalcitrantes (Bahia, Pará, Maranhão, Piauí e Cisplatina), e fazer-se reconhecer no plano externo. A preservação da unidade e o reconhecimento internacional, sabiam os brasileiros, seria muito mais difícil sem o concurso de D. Pedro. Esta primeira fase da independência do Brasil teve como objetivo principal afastar as tentativas de recolonização. Vemos, portanto, que não só se deve ao respeito pela pessoa de D. Pedro, a instalação da monarquia no Brasil recém-emancipado. Há uma série de fatôres atuantes.

As provincias do norte e nordeste foram dominadas graças às tropas mercenárias contratadas por D. Pedro, assegurando para a monarquia do Brasil independente a região que era responsável por mais de $60 \%$ das rendas nacionais na época - compreende-se porque a unidade brasileira era importante. Em 1823 tôdas as províncias mantêm-se sob a tutela de D. Pedro I. O Brasil superou nessa época uma das maiores ameaças de desintegração politica de sua História.

No plano externo o govêrno de $\mathrm{D}$. Pedro conseguiu o reconhecimento de Portugal em 1825, o da Inglaterra, e das outras nações. Não sem prejuízo de monta para a economia do Brasil. O acôrdo firmado com a Inglaterra de abolir o tráfico de escravo indispôs os donos de terras e de escravos contra D. Pedro, uma das causas importantes de sua abdicação.

Passados os primeiros momentos do seu govêrno liberal D. Pedro mostrou-se absolutista. A dissolução da Assembléia Constituinte em novembro de 1823 foi o primeiro sinal patente das intenções de D. Pedro. Foram suprimidas algumas conquistas liberais.

A Confederação do Equador em 1824 foi reprimida violentamente, instalando-se um verdadeiro regime de terror. Mais tarde, de 
forma violenta foi conservada a unidade territorial do Brasil. Só que desta vez muitos dos que trabalharam pela emancipação política de sua pátria foram cruelmente executados.

Tudo isso e mais a intervenção de D. Pedro no Prata, a proteção que êle dispensava aos portuguêses e sua preocupação com os problemas do trono português de sua filha D. Maria da Glória, fizeram desencadear sôbre o Imperador uma série de insubordinações regionais e principalmente uma violenta oposição dos grupos políticos no Rio de Janeiro. D. Pedro, tendo contra si um ambiente totalmente adverso foi levado a abdicar em 7 de abril de 1831. Com a abdicação e o período regencial consolidou-se a Independência do Brasil.

Os brasileiros no período regencial de 1831 a 1840 tiveram oportunidades de transformar o Brasil em República. No entanto a corôa foi conservada para o sucessor legal, D. Pedro de Alcântara. Como se explica isso? Existem várias razões. Primeiramente porque os elementos que assumiram o govêrno, os chamados liberais moderados, temiam a desordem estabelecida nas repúblicas americanas. As experiências latino-americanas atemorizavam as elites brasileiras. Diz Pereira da Silva que

"... o sistema republicano tanto mais repugnava à indole, aos costumes, aos interêsses e às aspirações do povo brasileiro, quanto o espetáculo das nações vizinhas constantemente revoltas e ensanguentadas pelas guerras civis e ambições de caudilhos, concorriam poderosamente para radicar o princípio monáquico" (8).

Por outro lado o Senado, vitalício e conservador, fazia tudo para interromper qualquer tentativa de avanço democrático (9).

Os movimentos de caráter republicanos como a Cabanagem, a Sabinada, a Balaiada, são sufocados da mesma forma que os movimentos radicais do Rio de Janeiro. Estes foram feitos pelas classes média e inferior. Observa-se em tôda ação repressiva do govêrno regencial o apôio da classe latifundiária alicerçando dessa forma o govêrno monárquico (10). Os tumultos republicanos ou federalistas criam o temor da desagregação nacional. O Marquês de Caravelas afirmava que só no poder moderador do rei residia a necessária eficácia, independente das paixões políticas dos partidos, para serenar as discórdias. Pregava o respeito à Constituição de 1824. Era seguido pela maioria da Assembléia (11).

(8) - Silva (Pereira da), História do Brasil: durante a menoridade de $\mathbf{D}$. Pedro II (1831-1840). 2a. ed., Rio de Janeiro, Garnier, 1878, p. 323.

(9). - Idem, Ibidem, passim.

(10) . - Cf. Sodré, op. cit., só um movimento insurreicional, o Farroupilha, contou com o apôio dos estancieiros e porisso resistiu por mais tempo.

(11). - P. da Sllva, op. cit., passim. 
Os senadores tinham que defender a constituição para segurança de seu cargo vitalício. A defesa de certos interêsses e privilégios levou os homens da Regência, invocando o perigo de anarquia é esfacelamento do Brasil, a conservarem a monarquia prolongando-a por mais algumas décadas.

Assim, a coroação do Imperador de 15 anos de idade, em 1840, foi feita com o objetivo de realizar uma ação centralizadora e consumar a frágil unidade conservada no Período Regencial. Vemos dessa forma, que no Brasil graças à instituição legada por Portugal a partir da transmigração bragantina, a monarquia é implantada no Brasil. Fatôres de ordem externa e interna, portanto, conjugaram-se na elevação ao trono de um monarca brasileiro.

\section{3. - A Independência da América Espanhola: a república e o retalhamento territorial.}

Na América espanhola houve luta pela autonomia antes de se pensar na forma de govêrno a ser adotada. O grande objetivo não era a república, mas uma equiparação à metrópole. Todavia as juntas e governos regionais proclamaram a Independência e a República.

Como no Brasil havia uma estrutura política, econômica e social interna afim com a monarquia. Havia uma forte opinião monárquica. San Martin, por exemplo, argentino educado na Europa, era partidário de que príncipes europeus bourbônicos ocupassem os tronos das novas nações americanas para evitar a anarquia

Bolivar, o libertador, também estudou na Europa; presenciou e impressionou-se fortemente com a coroação de Napoleão. No Congresso de Angostura em 1819 Bolivar expôs suas idéias constitucionais. Propunha a República, duas Câmaras, senado hereditário \& presidente vitalício com amplos podêres (12). Locke e Montesquieu acham-se presentes em Bolivar (13) mas a impressão causada pelo regime napoleônico e a idéia de Hamilton (14) influenciaram também as suas concepções de República fortemente centralizada. Era republicano na forma, mas com tendência monárquica e autoritária

(12) - - Cf. Dicionário de História de España. Madrid, Revista de Occidente S.A., 1952 - pg. 434-442.

(13). - Stoetzer (O. Carlos), El pensamiento politico en la América española durante el periodo de la emancipación (1789-1825). Las bases hispanicas $y$ las corrientes europeas. Madrid, 1966. Instituto de Est. Políticos 2 vol., passim.

(14). - Hamilton defendia a Idéia da presidência vitalícia nos Estados Unidos da América. 
pelo temor à desordem, à desunião e à caudilhagem que vê ao fim da vida instalarem-se nas repúblicas fragmentadas.

Francisco de Miranda revelou suas idéias através de seus projetos constitucionais que possuíam sempre um fundo arisiocrático e autoritário. Bernardo O'Higgins compartilhava das idéias de Miranda e não era sequer liberal. A constituição do Chile após a prociamação da república em 1818, foi feita por apenas 7 membros ligados diretamente a O'Higgins.

Vemos, portanto, que a concepção republicana dos líderes libertadores da América era um tanto confusa. Todos viam a necessidade de um govêrno fortemente centralizado. As primeiras constituições eram um misto de monarquia e república. Na prática, os caudilhos substituíam os monarcas. A guerra e sua excessiva duração fizeram passar à direção das novas nações os chefes militares e surge o caudilhismo como instituição.

Os governos centrais que se impuseram pela fôrça e não tinham o prestígio de um rei, causavam, em grande parte, as insurreições dêsse período agravando os interêsses regionais, resultando no retalhamento do mundo colonial espanhol. A tentativa de Bolivar de conservar a unidade colonial formando a Gran Colombia fracassou como fracassariam também as aspirações da Argentina de conservar o antigo vice-reinado; prevaleceram os particularismos e governos fortes, teòricamente republicanos .

No Brasil o regionalismo foi sufocado pelo poder central. Primeiro porque havia uma autoridade moral com forte aparato militar. Segundo, e êste é um fator muito importante, a relativa unidade geográfica facilitou a tarefa unificadora. No resto da América latina a diversidade geográfica é muito maior, dificultando o acesso e isolando naturalmente certos territórios.

Quando no Brasil foi proclamada a independência havia quem ocupasse o trono. Quando houve oportunidade de proclamar a república em 1831 já havia a experiência da América espanhola ensanguentada e subdividida. Então, o sentido unitário e a preocupação de evitar convulsões políticas prevaleceram na mente dos homens da regência.

\section{4. - A Influência inglêsa na independência da América Latina.}

Um outro problema que não pode deixar de ser tratado destacamente quando se analisa o processo de independência na América Latina é a influência inglêsa cujos aspectos já se esboçaran ao início desta análise. 
Depois da queda de Napoleão a América ibérica transformouse num dos setores mais importantes do comércio britânico. Por isso a Inglaterra via com bons olhos os movimentos que tendiam a cortar os laços entre a América e as metrópoles. Apoiava a desintegraçâo de um império para formar o seu próprio. As relações diretas e não através das metrópoles eram muito mais vantajosas para a ação econômica inglêsa.

A partir de 1817 o govêrno inglês passa a incentivar os insurrctos da América com armas, munições e técnicos. No aspecto internacional, depois de Canning substituir Castlereagh em agôsto de 1822, o govêrno inglês abandonou a ação sub-reptícia para agir abertamente tomando posição contra a política intervencionista da Santa Aliança. O'Higgins e San Martin receberam auxílio inglês. O domínio do Peru cristalizou-se com a cobertura naval do oficial britânico Cochrane, o mesmo que ajudou D. Pedro na consolidação do seu govêrno. Logo após a dissolução da assembléia em 1823 D. Pedro conseguiu auxílio financeiro da Inglaterra com o qual armou a repressão aos movimentos revolucionários. A mediação inglêsa no reconhecimento da Independência por Portugal foi importante. Os inglêses defendiam os seus privilégios patenteados no tratado de 1810 . Não queriam perder um vantajoso mercado para os seus produtos. Entre os fins do século XVIII até a primeira década do século XIX a Inglaterra conquistou e consolidou seu domínio econômico na América Latina, o que leva Pierre Chaunu a dizer que

"de 1797 a 1810 a América Ibérica tornou-se, e foi até 1914, a mais bela das colônias britânicas" (15).

\section{5. - Relações entre a monarquia e as repúblicas após a Independência.}

O Brasil imperial permaneceu isolado do resto da América não só na forma de govêrno, mas econômicamente também, dando as costas para os países latino-americanos e voltado para o Atlântico europeu. Podemos no entanto examinar as relações políticas do Brasil com os países do Prata. Faltam pesquisas para um relacionamento em têrmos globais de América Latina.

A tentativa consciente de imperialismo de D. João na América do Sul reconhecida até por Oliveira Lima (16) tem como resultado

(15). - Op. cit., pg. 210.

(16). - Op. cit., 19 volume. 
a ocupação da Banda Oriental que se completou em 1820 depois da derrota de Artigas tornando-se província do Reino Unido de Portugal, Brasil e Algarves. A Cisplatina foi uma das províncias que só reconheceram a autoridade de D. Pedro pelas armas, logo após 1822.

Em 1825 os cisplatinos buscam o apôio das Províncias Unidas do Rio da Prata (futura Argentina) declarando-se república separada do Brasil e incorporada às Províncias Unidas com as quais tinha muito mais em comum. A política de D. Pedro foi, então, orientada. no sentido de conservar o que fôra conquista de seu pai. A luta de D. Pedro foi infrutífera uma vez que as províncias do Rio da Prata e o Brasil concordaram em dar a Independência ao Uruguai em 1828, aprovando a sua primeira constituição em 1830 . Este foi o primeiro choque entre a monarquia brasileira e as repúblicas do sul.

Durante o período regencial só houve um incidente, com o presidente Manuel Oribe, em 1837, provocado pelo uruguaio que invocando as divisas do tratado de. Santo Ildefonso queria aumentar seu território. A questão ficou no terreno da diplomacia e em nada resultou nesse período.

A intervenção seguinte do Brasil no Prata foi para evitar a anexação do Uruguai pelo ditador argentino Juan Manuel Rosas e com o objetivo também de defender a liberdade de navegação dos rios platinos necessários ao Brasil para o acesso a Mato Grosso. Em maio de 1851 realizou-se uma convenção entre duas cidades rebeladas contra a tirania de Rosas (Corrientes e Entre Rios), o govêrno do Uruguai e o Brasil. A intervenção da monarquia foi fator decisivo para a derrubada do govêrno ditatorial de Rosas depois da Batalha de Caseros em 3 de fevereiro de 1852. Depois disso o Brasil não mais teve problemas com a Argentina, mantendo sempre ligações pacíficas.

Outro problema havido na região do Prata foi ainda no Uruguai devido às incursões de uruguaios em território brasileiro do sul. $O$ Brasil invadiu o território uruguaio e colocou no govêrno um elemento do partido colorado que se opunha ao partido Blanco de Aguirre, causador do incidente. Tomando o poder Venâncio Flôres reatou relações amistosas com o Brasil.

O acontecimento mais sério de que o Brasil participou na América Latina foi também na América Meridional envolvendo o Paraguai fortemente militarizado de Solano Lopez contra a Tríplice Aliança (Brasil, Argentina e Uruguai). Conflito sangrento iniciado em 1865, só terminou cinco anos depois com a derrota do Paraguai.

Em tôdas as questões internacionais entre o Brasil e as repúblicas não se observa uma ação imperialista brasileira. O Brasil saiu vitorioso de tôdas as relacõos bélicas no Prata mas não extraiu nenhum proveito. Ao contrário teve muitos prejuízos em materiais e homens. 
Devido à sua grande extensão, suas relações estreitas com a Inglaterra e principalmente pelo seu regime, o Brasil era visto por a!guns estadistas americanos como perigoso aos interêsses republicanos. Rosas exagerava; por questões óbvias, classificava o Brasil de representante da Santa Ailança na América. Êsse não era exatamente o pensamento das repúblicas que não obstante mantinham cautela. A politica externa brasileira do Segundo Reinado caracterizava-se por pronunciamentos solidários às repúblicas e pela sua auto-determinação.

Não obstante sua situação de país mais poderoso da América do Sul nunca conseguiu liderança por ser o único país monarquista. Por outro lado não era uma nação que inspirasse confiança total a Europa. A forma constitucional da monarquia brasileira estava dentro do sistema americano e não tinha, teòricamente, o caráter reacionário de muitas monarquias européias.

\section{6. - A volta do ideal republicano no Brasil.}

A ascenção de D. Pedro II ao trono marcou, depois da revolução praieira de 1848 em Pernambuco, o início de uma paz que se prolongaria por algumas décadas. A chama republicana da esquerda liberal da Regência foi completamente reprimida pela fôrça que a Monarquia deu ao govêrno central. A "Conciliaçãa" liderada pelo Marquês de Paraná ocupou, também, lugar importante na contenção da idéia republicana na medida em que, amenizando-se as lutas partidárias, qualquer movimento de caráter republicano não encontrou ressonância nas lides políticas. D. Pedro II impôs-se como rei não tanto pela sua seriedade e moral impecável, seus atributos, mas pela estrutura latifundiária e escravista que via na Monarquia sua estabilidade.

A cristalização da Monarquia Constitucional teve influências européias. O ímpeto republicano advindo da Revolução Francesa atenuara-se na própria Europa. A época vitoriana iniciada em 1837 e o grande surto industrial operado na Inglaterra sob a égide monárquica foi fator de prestígio do regime e a nação britânica foi modêlo para o Brasil. O constitucionalismo português, como o inglês, teve parcela de influência, na consolidação da Monarquia e erradicação da idéia republicana no Brasil. O único país republicano na América com sólidas bases políticas e econômicas eram os Estados Unidos, mas qualquer tentativa de aproximação do país norte-americano foi, por muito tempo, anulada pela habilidade inglêsa. Esse rechaço inıplicou em afastamento da idéia da República. 


\section{7. - A Guerra da Tríplice Aliança e o republicanismo no Brasil.}

O ressurgimento da idéia republicana no Brasil coincide com o fim da Guerra da Tríplice Aliança em 1870. O contacto com o Uruguai e principalmente com a Argentina que superara a fase do caudilhismo pesou, com certeza, no reavivamento do ideal republicano em hibernação desde o período regencial. Aparece no cenário político brasileiro o elemento militar, até então submisso a $\mathrm{D}$. Pedro e ao seu estado maior de políticos, no sentido de não terem acesso aos quadros político-administrativos. Ao contrário, nas repúblicas sulamericanas o militar ocupava posição de destaque.

O contacto mais estreito com países da América Meridional e o estado de guerra pelo qual passaram os militares despertaram as suas gerações mais novas. A filosofia positivista. por outro lado, deu uma concepção mais atuante ao papel histórico da classe militar. Aos poucos elevou-se o exército na hierarquia da sociedade brasileira do século XIX e deu ambiente para a chamada questão militar, fator importante na proclamação da República .

Os primeiros entremecimentos entre o exército e o govêrno monárquico iniciaram-se durante a Guerra da Tríplice Aliança.

Tendo a questão militar papel de destaque na proclamação da República e fruto em grande parte da citada guerra, lícito é concluirmos haver parcela importante de influência das repúblicas platinas na proclamação da República do Brasil.

\section{9. - O Manifesto Republicano.}

Publicada pelo jornal $A$ República em 1870, o manifesto republicano patenteava o desêjo de alguns brasileiros de igualar o Brasil aos países da América (17). E' trecho do manifesto:

"Somos da América e queremos ser americanos. A forma de 'govêrno (a monárquica) é, na sua essência e na sua prática, antinômica e hostil ao direito e aos interêsses dos Estados americanos. A permanência desta forma tem de ser forçosamente, além de origem de opressão no interior, a fonte perpétua de hostilidade e de guerras com os povos que nos rodeiam" (i8).

(17). - Além do contato com os países do Prata outro fator a prestigiar o ressurgimento do Ideal republicano fol o impulso desenvolvimentista dos Estados Unidos da América depois da Guerra de Secessão, o que abriu um crédito de confiança no seu sistema governativo.

(18) . - Bello (José Maria), Históriada República (1889-1954). 5a. ediç๘o, \$̊̆o Paulo, C. E. Nacional, 1964 pg. 20. 
O restante dêsse manifesto é tímido e moderado - muito dentro do espírito de precaução da época - revela, não obstante, a preocupação de brasileiros empolgados com o regime republicano de colocar o Brasil em plano de igualdade com as nações americanas. E o despertar de uma consciência americana.

O modêlo republicano influenciou também os espíritos românticos do abolicionismo, na medida em que ligam a liberdade à República desprestigiando assim, a monarquia.

Quando o interêsse regional e a ordem econômica e social interna do Brasil aliaram-se aos fatôres ideológicos de ordem externa houve a proclamação da república.

Embora muitos vícios da monarquia tenham permanecido na época republicana, a abolição da escravatura e a proclamação da República igualaram o Brasil às demais nações latino-mericanas do século XIX. 